\title{
RHETORICAL STRUCTURE AND PERSUASIVE LANGUAGE IN THE SUBGENRE OF ONLINE ADVERTISEMENTS
}

\begin{abstract}
This paper aims to reveal the rhetorical structure and the linguistic features of persuasive language in online advertisements of electronic products. Nowadays, the bulk of e-commerce is carried out in English, and it is often the case that non-native speakers are required to write different text types for various professional purposes, including promotional texts. This need has prompted the present study and the results have been used to build software to help native speakers of Spanish when writing promotional texts in English. The analysis reveals that these texts typically have two main rhetorical moves: one for identifying the product and another one for describing it. The latter move is further divided into two steps: one including objective features (size, weight, etc.) and the other focusing on persuading the potential customer. This is mainly achieved with the use of a relatively informal style (imperatives, contractions, clipping, subject/auxiliary omissions, etc.) and lexico-grammatical elements conveying positive evaluation (multiple modification, multal quantifying expressions, etc.). The findings show that online advertisements of electronic products may be regarded as a specific subgenre with particular macro- and microlinguistic characteristics, which have been identified in this paper for technical writing assistance.
\end{abstract}

Keywords: online advertisements, rhetorical move analysis, persuasive language, technical writing.

\section{Introduction}

It is a well-known fact that for non-native speakers a good command of English is a must in our globalized world. English has been acting as a lingua franca for several decades now in all areas of intercultural communication, not only in the fields of science and technology or in academic research, but also in everyday activities such as trade, education, tourism, personal exchanges between individuals with different mother tongues, and so on. Furthermore, many of these activities are carried out on the internet, for instance, e-learning, online shopping or social networks, with technological progress providing users with more and more sophisticated devices which enable them to engage in these types of communicative acts anywhere and at any time. 
It is also becoming increasingly common that native speakers of Spanish who work in various professional environments and have an intermediate level of English are required to produce texts for specific purposes in their own fields of interest in English. The present study is prompted by this specific need: to assist these professionals in writing techniques. The ACTRES project (http://actres.unileon.es) currently in progress at the University of León, Spain, aims at building software for professional writing in a number of fields, including medical abstracts, meeting minutes and online advertisements, among others, since "the participation of individuals in disciplinary cultures demands an informed pragmatic understanding of how to construct and interpret key genres" (Hyland, 1998, p. 453).

The writing of online advertisements requires knowledge of the typical rhetorical structure of this text type as well as of the linguistic resources available in English to persuade the reader to buy certain products online. An adequate selection of lexical items and a proper combination and distribution of objective and persuasive information are crucial for directing the reader towards taking the decision to purchase a particular item. This paper deals with the rhetorical structure and the expression of persuasion in English as found in online advertisements of visual electronic devices that are used in leisure activities: digital cameras, video-cameras, television sets, e-book readers and digital frames. These products share one characteristic: they all possess a display screen and therefore have a number of terms and specifications in common, making them more easily comparable.

A corpus-based methodology is adopted in this study: an ad hoc EnglishSpanish comparable corpus of 100 advertisements of small electronic devices was compiled to study the persuasive language found. The working procedure included several stages. First, the texts included in the corpus were tagged for their rhetorical moves following Swales' move step model (Swales, 1990, 2004) to enable crosslinguistic comparison. Secondly, a specially designed browser was used to extract lexical data by move, step or substep. Finally, the persuasive phraseology in English in the step called 'persuasion' was analyzed.

\section{Theoretical background}

\subsection{The concepts of genre and move step rhetorical analysis}

As Mauranen states, "culture influences writing habits in an important way. This is because writing clearly is a cultural object, existing only in the social world of 
humans, as a product of social activities." (Mauranen, 1993, p. 4). Texts used in the context of professional environments tend to be written following certain conventions that make them recognizable as belonging to a particular genre. These conventions share an overall structure where all the texts contain the same rhetorical elements with similar purposes in the same, or nearly the same, order. This means that each discourse community develops a particular internal structure for each text type. For example, all the online advertisements in our corpus share a similar arrangement of purposeful communicative units determined by the context of use.

Within the field of discourse analysis, the study of different genres has been approached from a number of linguistic perspectives, and we will follow a functional view in this paper for the study of the subgenre of online advertisements. Functional approaches to language have a long-standing tradition in British scholarship (Firth, 1957; Halliday, 2004). The importance of the context, the participants in the communicative event, and the field of discourse are all aspects of language variation which highlight the social function of language as the dominant feature of human communication. Within this framework, John Swales set the foundations of the study of discourse genres with his seminal work on the introduction of research articles (1990), establishing the communicative purpose as the main feature shared by all the texts belonging to the same genre. More recently Bhatia has defined genre as referring essentially to "language use in a conventionalized communicative setting in order to give expression to a specific set of communicative goals of a disciplinary or social institution which gives rise to stable structural forms by imposing constrains on the use of lexico-grammatical as well as discoursal resources" (Bhatia, 2004, p. 23).

A number of approaches have attempted to describe the communicative units in particular genres and to provide a framework for studying rhetorical structures in different text types. One of these approaches is Swales' move step rhetorical analysis, which proposes a hierarchical classification involving moves and steps, which other authors have further developed or adapted for their own purposes, studying different sections of research papers (Salager-Meyer, 1990; Brett, 1994; Dudley-Evans, 1994) or other genres like business letters (Bhatia, 1993; Hiranburana, 1996; Zhu, 2001; Vergaro, 2011), grant proposals (Connor \& Mauranen, 1999), application letters (Upton \& Connor, 2001) and letters of recommendation (Precht, 2000). Many of these rhetorical studies have been carried out from a cross-linguistic perspective involving English and Spanish and focusing on different genres, such as scientific abstracts (Martín-Martín, 
2003, 2005; López-Arroyo et al., 2007), academic book reviews (Suárez \& Moreno, 2008), medical research papers (Williams, 2012), football match reports (DíezFernández, 2009) and so on.

According to Biber et al., a move "refers to a section of a text that performs a specific communicative function. Each move not only has its own purpose but also contributes to the overall communicative purpose of the genre" (Biber et al., 2007, p. 23). A move can be further divided into steps and substeps to give an account of more detailed rhetorical structures. All these purposes together contribute to shaping the lexical content and style of texts in a particular genre so that all the texts exhibit "various patterns of similarity in terms of structure, style, content and intended audience" (Swales, 1990, p. 58). In this paper we have followed Swales' move step model for the rhetorical analysis of online advertisements in English.

\subsection{The subgenre of online advertisements}

Within the genre of advertisements, we may consider online advertisements as a particular discourse subgenre, along with other subgenres including print, TV and radio advertisements. Additionally, Janoschka points out less common carriers of advertising messages, such as "bags, hot-air balloons, tickets and vouchers, shopping carts or buses and trains in the public transport sector" $(2004$, p. 9). All advertisements share the communicative purpose of presenting the product in such a way that the reader is convinced of its value and considers buying it: "Advertising communication is a social activity which functions in our culture in order to facilitate the selling of products and/or services" (Fuertes-Olivera et al., 2001, p. 1294).

The differences between online advertisements and other types of advertisements are mostly due to the medium employed and the context of use. "There is a noticeable similarity between conventional advertising and [...] online advertising, although online ads tend to apply a more interactional-conversational language approach. However, differences occur with regard to language use, message flow, and types of direct user addressing" (Janoschka, 2004, pp. 9-10).

Following Cook's classification (2001), we describe below online advertisements according to a number of criteria, such as medium, type of product, technique, consumer profile and so on. 
1. Medium: The fact that they appear on the Internet (and not in magazines, radio, television, newspapers or printed books) greatly determines their internal structure.

2. Item advertised: product vs. non-product ads. Online advertisements may serve to sell products, or they may offer services.

3. Technique: Products or services may be sold on the internet using the hardsell technique, i.e., making a direct appeal to the customer, or using the soft technique which "relies more on mood than on exhortation, and on the implication that life will be better with the product" (Cook, 2001, p. 15).

4. Appeal type: reason vs. tickle. "Reason ads suggest motives for purchase. [...] Tickle ads on the other hand appeal to emotions, humor and mood" (Cook, 2001, p. 15). Online advertisements may be of both types.

5. Consumer profile: This parameter refers to the socio-economic background of the consumers targeted. In the case of online advertisements we are talking about computer literate adults who actively seek out these texts, instead of simply coming across them, such as in the case of print, TV or radio advertisements. This fact is relevant because it determines the type of language employed, that is, the writer does not particularly need to think of attracting the reader's attention with catchphrases or any other devices, as the reader has previously decided to look for this particular ad.

6. Length: long copy vs. short copy. Online advertisements belong to the long copy group because unlike other types of advertisements, they can be defined as more descriptive and informative texts, rather than simply short attention-grabbing advertisements.

Online advertisements share a number of textual and contextual features specific to the subgenre. Textual features comprise all the linguistic elements used to describe the product and convince the potential customers. In addition to these verbal elements, in the case of online advertisements, many non-verbal elements are at play too: pop-up windows, hyperlinks, pictures, banners, videos, demos and so on. A good overview of the various media in which advertisements may appear can be found in Myers (1999). Previous research on web advertising demonstrates how this form of advertising enhances interactivity and multi-linearity enabling users to "select their own path and create their own coherence" (Janoschka, 2004, p. 190). Other authors have focused on 
the pragmatic implications of transferring offline discourses, including advertisements, to online discourses (Yus, 2011).

\subsection{The persuasive language of advertising}

For Bhatia (2004, p. 60), there is a clear trend towards an increase in the number of promotional strategies in texts that are traditionally considered non-promotional, or in mixed text types, such as our advertisements of electronic products, which present both an information-giving function and a promotional function: "In text-typological terms, the advertisement seems to be better represented as a continuum of text functions fluctuating between 'informing' and 'manipulating'” (Hatim, 1990, p. 117). Thus, promotional genres in general have two main parts, one describing the product to be sold and the other one evaluating it positively to convince the reader to purchase it.

Because the intentionality in writing these advertisements is to convince potential customers to buy the products advertised, we may consider these texts at least partly argumentative in nature, with a number of specific linguistic devices required to achieve persuasion.

Persuasive language therefore tends to be creative and attention-drawing, exploiting language resources to the maximum with catchphrases, emotive words, informal expressions and striking metaphors and comparisons to appeal to the readers. The medium is primarily written in the case of online advertisements, yet it is frequently processed as if it were oral (Janoschka, 2004). This implies that language which is typical of colloquial style is used to get closer to the potential customers, for example by addressing mass audiences as though they were individuals through inclusive language usage. This strategy is what Fairclough (1989) calls 'synthetic personalization': “a compensatory tendency to give the impression of treating each of the people 'handled' en masse as an individual. Examples would be air travel (have a nice day), restaurants (welcome to Wimpy!)...” (1989: 62). Other authors (Fuertes Olivera et al., 2001; Janoschka, 2004) have provided lists of some of the most frequent features of the persuasive language found in advertisements, including commands, rhetorical questions or alliteration.

\section{Material and methods}

\subsection{Corpus data}


This study is a corpus-based analysis. Our corpus contains 100 texts in English and 100 in Spanish, comprising 45,491 words in English and 33,628 in Spanish. This difference in size is not relevant for our purposes, as there is the same number of texts in each language. The texts are advertisements of electronic products sold on the internet, extracted from the web sites of large retail companies, such as El Corte Inglés, Carrefour and Pixmania in Spain, and Walmart, Best Buy and Sears in English-speaking countries. The texts were originally written in each language and are not translations, neither do they advertise exactly the same products, but rather a variety of items, brands and models. All the texts were collected between 2010 and 2011.

The corpus is divided into five subcorpora according to the type of electronic device advertised (20 texts per device and language): digital cameras, video-cameras, television sets, e-book readers and digital frames. This type of product represents small appliances associated with leisure activities, not household appliances such as fridges, dishwashers or washing-machines. They are relatively simple appliances targeting a wide range of potential customers and therefore these products are often sold online, also because shipping is inexpensive and they do not require major installation services. All these products share one characteristic, namely they all possess a screen and thus have a number of terms and specifications in common, making them more comparable.

Our electronic products are mainly sold through the hard-sell technique, that is, making a direct appeal to the customer. The dominant trend in our advertisements is reason, although occasionally the persuasive language also appeals to emotions. As for the profile of the consumers targeted, they are mainly computer literate adults with sufficient economic resources to afford electronic products.

Regarding the extra-linguistic elements present in our online advertisements of electronic products, these include pictures of the devices advertised (between 1 and 3) and other elements such as pop-ups, color codes, and so on. The complex layout of these web sites, with many hyperlinks (see Appendix A), often made it difficult to decide which parts to include in the corpus as a single text. It was decided to include the main body of the text but to exclude commercial details such as shipping information, prices, offers, and so on. This information on commercial details was taken for granted and will not be focused on in the analysis which follows.

We are aware of the fact that persuasion is not achieved exclusively by means of linguistic resources; all the visual elements also contribute to the communicative function of advertising. However, the aim of this paper is to obtain the linguistic 
information necessary to express persuasion in English so that native speakers of Spanish may construct their own online advertisement. We do not believe that the nonverbal elements are likely to cause any problems for Spanish speakers, as online advertisements are similar in that aspect in both cultures. Therefore, the semiotic aspects of online advertising are beyond the scope of this paper. The difficulties lie in the verbal elements, which will be the focus of this linguistic study.

\subsection{Procedure}

\subsubsection{Rhetorical analysis}

Both corpora were tagged for rhetorical moves to compare the internal structure of this text type in English and Spanish. Subsequently, the English subcorpus was used as the source of empirical data for the analysis of persuasive linguistic features in English, whereas the Spanish subcorpus was employed for reference and comparison, given that the final users of the applications derived from our research are native speakers of Spanish.

A preliminary analysis of ten texts in each language provided a tentative list of moves, steps and substeps. This list was based on a combination of linguistic evidence and the understanding of the text as part of its genre (Dudley-Evans, 1994, pp. 226227). The identified rhetorical structure was fed into a specifically designed computer program (ACTRES Text Tagger) which enabled us to tag all our texts with the corresponding rhetorical move. A number of software solutions for tagging already exist on the market (e.g., AntMover, MAXQDA). However, on our multi-disciplinary research team there are IT engineers and linguists, so an ad hoc tagger and its corresponding browser were built to meet our specific needs for the analysis of our texts.

Each text was processed individually and a particular rhetorical label was assigned to each section of the text, one by one. The moves identified range from single words to whole paragraphs. Also, it was often the case that a chunk of text within a paragraph belonged to a different move from the rest of the paragraph (see Appendix B). Once all the texts had been tagged, the linguistic data could be sought and retrieved automatically in each separate section or in a combination of sections. Thus, it became possible to identify distributional patterns across rhetorical moves or in one single move or step. It was found that the same rhetorical structure applied both to English and to 
Spanish. The following is a complete list of rhetorical tags obtained and used for the analysis:

\section{MOVE 1: <IDENTIFYING PRODUCT AND PURPOSE $>$}

○ Step 1. <referring to the manufacturing company $>$

○ Step 2. $<$ naming the product $>$

○ Step 3. <stating the applications $>$

○ Step 4. <illustrating the product with a picture $>$

\section{MOVE 2: <DESCRIBING THE PRODUCT $>$}

○ Step 1.<objective characteristics>

- Substep 1. $<$ listing features $>$

- Substep 2. $<$ listing models $>$

- $\quad$ Substep 3. $<$ listing data sheets $>$

- Substep 4. $<$ listing extra options $>$

○ Step 2. <persuasive characteristics $>$ :

- Substep 1. <evaluating the product positively>

- Substep 2. < comparing the product with other similar products $>$

This paper deals mainly with persuasive language, so our focus here is on Step 2 within Move 2, that is, on persuasive characteristics associated with description of the product.

\subsubsection{Lexico-grammatical analysis}

After the tagging process, a tailor-made browser (ACTRES Corpus Browser) was used to extract linguistic information from within the different rhetorical moves in the English subcorpus. Because of the aim of the paper, only the English subcorpus was analyzed for the lexico-grammatical features of the persuasive language. The browser provides statistical information (for example, on the length of each step or substep), and it also functions as a concordancer enabling us to look for specific linguistic items in one particular rhetorical move, step or substep. This means that it is possible to identify patterns of use for certain words that occur more often in one move than in another. 
This software supplies all this information automatically and allows us to export the concordance lines to Word documents or PDFs.

For the purpose of this paper, we have only searched for linguistic items in the persuasive section (Move 2, Step 2), as this is the part where we expect more occurrences of this type of language. The starting point was to read each chunk of text labeled as persuasive and spot all the lexico-grammatical features somehow associated with persuasion. The final exhaustive list of persuasive items was then classified by part of speech and used as input for searches to determine their frequency of occurrence and their collocates. Those items occurring less than five times in the persuasive substep were not considered for further study. The remaining items were used to construct an inventory of persuasive resources in the English language. The findings have enabled us to draw a number of conclusions concerning the lexico-grammatical means available for expressing persuasive meanings in online advertisements.

\section{Results and discussion}

\subsection{Rhetorical structure in English and Spanish online advertisements}

Previous studies on the rhetorical structure of advertisements or similar genres (Bhatia, 2004; Barron, 2006; Vergaro, 2011; Zhou, 2012) have provided a number of suggested moves that may be present in these types of texts, including those detailing the product or service by identifying, describing and evaluating it positively. As expected, no negative features of the product are ever included in these texts, as they are not written by an independent person, but by the company or retailer wishing to sell the product.

Table 1 shows the percentages of occurrence of each move, step and substep identified in our English and Spanish online advertisements.

\section{Table 1}

Percentages of occurrence of the rhetorical moves in English and Spanish online adverstisements.

\begin{tabular}{|l|c|c|}
\hline Rhetorical move/step/sub-step & $\begin{array}{c}\text { Percentage of } \\
\text { English texts } \\
\text { containing the }\end{array}$ & $\begin{array}{c}\text { Percentage of } \\
\text { Spanish texts } \\
\text { containing the }\end{array}$ \\
\hline
\end{tabular}




\begin{tabular}{|c|c|c|c|}
\hline & & move/step/substep & move/step/substep \\
\hline \multirow{4}{*}{$\begin{array}{c}\text { Move 1: } \\
\text { Identifying } \\
\text { product and } \\
\text { purpose }\end{array}$} & Name of company & $22 \%$ & $30 \%$ \\
\hline & Name of product & $100 \%$ & $100 \%$ \\
\hline & Applications & $11 \%$ & $11 \%$ \\
\hline & Picture & $100 \%$ & $100 \%$ \\
\hline \multirow{8}{*}{$\begin{array}{c}\text { Move 2: } \\
\text { Describing the } \\
\text { product }\end{array}$} & Objective characteristics & $100 \%$ & $100 \%$ \\
\hline & - $\quad$ Features & $100 \%$ & $100 \%$ \\
\hline & - $\quad$ Models & $9 \%$ & $2 \%$ \\
\hline & - Data sheets & $46 \%$ & $24 \%$ \\
\hline & - $\quad$ Extra options & $1 \%$ & $2 \%$ \\
\hline & Persuasive characteristics & $75 \%$ & $71 \%$ \\
\hline & - $\quad$ Positive evaluation & $73 \%$ & $68 \%$ \\
\hline & - Comparison & $10 \%$ & $12 \%$ \\
\hline
\end{tabular}

Our online advertisements presented two compulsory moves: 'identifying product and purpose', on the one hand, and 'describing the product', on the other. Each electronic product needs to be presented to the reader so that the potential customer can easily identify what the product is and how it is used. The name and at least one picture of the product are compulsory elements in both corpora with $100 \%$ of occurrences. In contrast, mentioning the manufacturing company or the applications of the product seems to be optional. Only $22 \%$ of the English texts and 30\% of the Spanish texts include the name of the manufacturing company in the advertisement. In the case of applications, $11 \%$ of the texts included this step in both languages, a low priority when it comes to writing this text type. The nature of the products included in our corpus everyday household devices - makes the step of applications unnecessary in most cases, that is, everybody knows what a television is for; in more specific models like professional cameras, mentioning the applications appears to be more necessary (e.g., $a$ camera suitable for metallurgical microscopy).

Promotional discourse has long been perceived to be slowly creeping into other types of discourse, thus illustrating the " 'colonizing' tendencies of advertising discourse" (Fairclough, 1989, p. 199). The main body of all advertisements consisted of a descriptive move, further subdivided into two sections: one including the objective characteristics of the product and the other focusing on the persuasive aspects of the 
advertisement. In other words, the texts are a combination of "information-and-publicity or telling-and-selling" (Fairclough, 1992, p. 117), which can be considered pragmatic constructs in the discourse of advertising (Simpson, 2001). Bhatia (2004) highlights the complexity of professional communication today and, in particular, the hybrid nature of promotional and advertising texts that combine information with promotional discourse.

The objective characteristics appear in $100 \%$ of texts in both corpora, whereas the persuasive step occurs in $75 \%$ of the English texts and $71 \%$ of the Spanish texts. Our texts are all highly technical and therefore include the specifications and factual information related to the product; however, the data reveal that not all of the texts present persuasive language in an equally explicit way.

Step 1 on objective characteristics includes features, models, data sheets and extra options as separate functions. In features we include the technical specifications of the electronic products; models refer to the different variations of the same product; by data sheets we mean the PDFs with further technical information on the product; extra options are all the accessories that can be bought together with the product.

Only two substeps had high priority: features was found to be obligatory (in $100 \%$ of cases in both languages); data sheets were found in $24 \%$ of the Spanish texts and $46 \%$ of the English texts. This difference means that native speakers of Spanish writing online advertisements in English should consider the inclusion of a data sheet in their texts. The other two substeps (models and extra options) were of very low priority in both languages. Models occurred in only $2 \%$ of the Spanish texts and $9 \%$ of the English texts, and extra options occurred in $2 \%$ of the Spanish texts and $1 \%$ of the English texts. This similarity in frequency reveals that these particular steps will not create problems for Spanish writers.

As for Step 2 in Move 2, the persuasive section, the main substep here is the one including the positive evaluation of the product, which appears in $68 \%$ of the Spanish texts and $73 \%$ of the English texts. This percentage is lower than expected in both languages when considering advertisements, whose main function is supposed to be persuasive. This finding may be due to the fact that in some of our sources these texts were shorter than others and included almost exclusively descriptive features of the electronic products, with little space for persuasion per se. In these cases, the technical language dealing with the objective characteristics of the devices seems to be dominant and the persuasive content is much less explicit. 
In any case, we noticed that the persuasive component is slightly more common in English than in Spanish ( $73 \%$ vs. $68 \%$ of texts), and, in addition, it shows clearer boundaries with other sections in the texts, in particular with the objective characteristics, whereas in Spanish these two parts are often intertwined in the same paragraph. These findings confirm previous results obtained in English - Spanish contrastive rhetoric studies based on other genres, which have revealed "a generally more explicit textual rhetoric" in English (Valero-Garcés, 1996, p. 279). Similar results have been found in other language pairs including English, for example EnglishFinnish (Mauranen, 1993).

The product sold is compared with other similar products or previous models in $12 \%$ of texts in Spanish and in 10\% of texts in English, making this substep low priority. This demonstrates again that the rhetorical structure of this text type in both languages is similar because the figures are almost the same for English and Spanish in most moves, steps and substeps. To conclude, it may be said that no major differences have been identified in the rhetorical structure of online ads in English and Spanish.

In the next section we will present in greater detail the results of the analysis of the substep devoted to positive evaluation.

\subsection{Persuasive language in English online advertisements}

As mentioned previously, nearly three quarters of our texts contain a substep devoted to positive evaluation. This section accounts for about one quarter of the total amount of running text in both languages (25.85\% in Spanish and 22.45\% in English). The percentages are similar in the two languages, thus showing that persuasive language in this text type is equally important in both cultural backgrounds.

The lexico-grammatical analysis was carried out exclusively on the English data (approximately 10,000 words) because the main aim of this paper is to identify the linguistic resources available in English to express persuasive meanings in online advertisements of electronic products, so that native speakers of Spanish may use them when writing in English. In this paper, we have divided the persuasive elements found into two groups, each representing either the field of persuasion or the tenor of persuasion in these types of texts, in Hallidayan terms. The field refers to the topic and represents the ideational function of language, and the tenor refers to the relationship between the writer (the company advertising the product) and the reader (the potential customer), that is, the interpersonal function of language. 


\subsubsection{Positive evaluation}

In this section we will present a number of linguistic resources that have been found to contribute positive evaluation in our online advertisements. Table 2 shows a list of the most relevant elements indicating positive evaluation related with the field of discourse.

\section{Table 2}

Linguistic elements indicating positive evaluation.

\begin{tabular}{|l|l|r|}
\hline \multicolumn{2}{|l|}{ Positive evaluation (ideational function) } & Number of cases \\
\hline Discoursal elements & Emphatic enumeratives & 95 \\
\hline Syntactic elements: NPs & Multiple modification & 64 \\
\cline { 2 - 3 } & Quantifying expressions & 49 \\
\hline Syntactic elements: clauses & -ing clauses & 27 \\
\cline { 2 - 3 } & Verbless clauses & 17 \\
\cline { 2 - 3 } & -ed clauses & 11 \\
\hline Semantic elements & References to familiar objects & \\
\hline
\end{tabular}

Table2 includes the data on the most frequent semantic, syntactic and discoursal resources used to express positive evaluation and thus contribute to the persuasive force of the move. The positive evaluation is most often achieved by mentioning several different qualities, properties and/or characteristics of the product advertised in the same sentence or paragraph. As a consequence, one frequent cohesive resource used is that of discourse markers emphasizing the very many benefits of the product sold, for example enumerations (95 cases), in addition to ...; not only ... but; also; as well; plus; even; additionally; and so on. Other phrasal or clausal resources also present this emphatic enumerative function: Another plus is; And let's not forget the built-in flash and video light which help you capture video; The advantages of flash memory go beyond the added recording time; that's not all it offers; and so on.

Multiple modification of a single noun phrase is another notable resource conveying positive evaluation (64 occurrences). This implies the coordination of two or more adjectives in a single noun phrase, as in Simple, versatile software; this sleek, 
compact camcorder comes fully equipped, and many of these adjectives are compounds, for example: multi-talented, user-friendly laboratory workhorse; a thrilling, once-in-alifetime shot; and so on. Authors like Rush (1998) have also highlighted the complex noun phrase structure found in advertisements where "the descriptive premodifier (and postmodifier) is mainly used to give colorful and attractive descriptions of the product or service, and so communicates more on an emotive level" (Rush, 1998, p. 161). This author also points out the high frequency and variety of compound adjectives.

Also, there is a huge range of quantifying expressions with positive connotations (usually with reference to high quantity or degree) which greatly contribute to the persuasive effect of our texts (49 cases): a broad array of; a whole/-huge range of; a host of high quality web services; a vast display size; a variety of; a generous selection of; plenty of; innumerable; dozens; hundreds; thousands; a million; and so on.

One peculiar feature of these persuasive texts is the abundance of non-finite clauses containing positive information of the product sold, including -ing, -ed and verbless clauses (50 cases in our corpus). Back in the 1960s, Leech (1966) noted the relevance of non-finite clauses in advertising discourse. These clauses tend to occur in sentence-initial position and function as scene-setters for the rest of the sentence:

- Featuring a stunning 5-inch display and lightweight design, the Reader Pocket Edition easily slides into a purse or jacket pocket; Add a voiceover to narrate your footage when editing on a PC.

- Finished with a sleek black bevel, the Sandstrom S8DPF10 8" Digital Photo Frame will display your favourite moments with style; Pre-loaded with 100 ready to go classics, this e-Reader is an obvious buy.

- Simple to operate with Samsung's fun and intuitive Star Light touch buttons, ...; Easy to use, the EXi Blue camera can be installed and operational within minutes...

As for the semantic elements, we have found several cases of references to familiar objects. In addition to precise units of measurement referring to the size, weight and so on of the product advertised, for example 7" Digital Photo Frame! (something which is more common in the step devoted to objective characteristics), in the persuasive section we find a number of vague references to the physical properties of the product to make it more familiar for the reader and so that the reader can get a better picture in their mind as to what the product is like, for example comparing the product 
with a deck of cards (about the size of a deck of cards) or specifying that it can fit in a familiar place (Its elegant, lightweight design is small enough to slip into a purse or jacket pocket; you can have a portable library in the palm of your hands) or comparing its shape to that of the grip of a pistol (And let's not forget its comfortable pistol grip form factor that fits easily in your hand for hours on end of shooting.).

The results show that enumerative resources are the most frequent linguistic elements employed to emphasize positive evaluation, followed by two other means with the common aim of accumulating a number of positive characteristics of the electronic product sold in the advertisement: multiple modification and multal quantifying expressions within the noun phrase. Non-finite clauses, in particular-ing clauses, are also a frequent grammatical structure employed in these texts to present a compact summary of the advantages of the product. All of these elements contribute to the persuasive function of this text-type.

\subsubsection{Informal style}

On the interpersonal dimension, the English online advertisements in our corpus are written in a rather informal style, which reminds us of spoken interaction. This is probably a conscious decision by the authors, in an attempt to get closer to the potential customers of their products, by making the message more personal. The use of the $2^{\text {nd }}$ person pronoun contributes to making customers feel the message is directed at them individually, building familiarity with the use of the pronoun (Myers, 1994, p. 52). The main linguistic resources found contributing to an informal style are listed in Table 3.

\section{Table 3}

Linguistic elements indicating informal style.

\begin{tabular}{|l|l|r|}
\hline \multicolumn{2}{|l|}{ Informal elements (interpersonal function) } & Number of cases \\
\hline \multirow{2}{*}{ Direct form of address } & $2^{\text {nd }}$ person you & 193 \\
\cline { 2 - 3 } & Imperatives & 129 \\
\hline Punctuation & Contractions & 64 \\
\cline { 2 - 3 } & Exclamation marks & 47 \\
\cline { 2 - 3 } & Ampersand (\&) & 9 \\
\hline Language play & Puns, catch phrases & 45 \\
\hline
\end{tabular}




\begin{tabular}{|l|l|r|}
\hline & Alliteration & 13 \\
\hline Reductions & Clipping & 18 \\
\cline { 2 - 3 } & Lack of auxiliaries in questions & 4 \\
\cline { 2 - 3 } & Subject omission & 4 \\
\hline
\end{tabular}

The most noticeable feature of informal and direct style of address in our texts is the use of the second person you (193 cases) and the use of imperatives (129 cases), which means that, on average, every text contains two instances of each resource, for example:

- You can feed photos directly into the SPF-1000W 10" Digital Photo Frame.

- Simply press one button to record, and when you're finished, another to project.

- With its built-in digital Freeview HD tuner, you'll never be short of entertainment choices.

- Discover the full potential of modern television with the remarkable Panasonic VIERA TX-P50ST30B 50" Full HD Plasma 3D TV!

- Surround yourself with vivid, colourful memories of family, friends and fun with the Sandstrom S8DPF10 8" Digital Photo Frame!

- Keep your favourite memories close and safe with the Sandstrom S7IDPF10 7" Digital Photo Frame!

- $\quad$ Don't Let Sun Glare Ruin Your Recording.

Fuertes-Olivera et al. (2001) have also signaled the frequency of certain sentence types and structures in the persuasive language found in advertisements, including commands and rhetorical questions. The frequency of use of the second person singular relates to Fairclough's (1989) concept of synthetic personalization.

Next in frequency of occurrence, a number of punctuation marks were found to signal informal language, 120 cases in all in our corpus, mainly of the following types:

- Contractions: - it's that simple; There's no need to worry; If you're on a tight budget you'd do well to choose the Matsui M15DIGB19 15" HD Ready LCD TV! 
- Exclamation marks: The next generation of entertainment starts here with the LG 42LX6900 42" Full HD 3D LED TV!; Who knows what slideshow surprises you'll find!; When it comes to enjoying photos with effortless ease, you can trust Kodak and the Pulse 10" Touchscreen Digital Photo Frame!

- Ampersand, instead of the full word 'and': Features $\underline{\&}$ specs; The camera offers Touch $\underline{\&}$ Track; $24 p \underline{\&} 30 p$ Frame Modes.

In addition, we found 58 instances of language play in our online advertisements; these are phonological and lexical devices used to attract the attention of the reader through witty expressions or alliteration:

- Puns, catchphrases: The Panasonic HDC-SD60 High Definition Camcorder (Silver) is an entry-level HD camcorder for those looking to break into high def recording without breaking the bank; A lot of

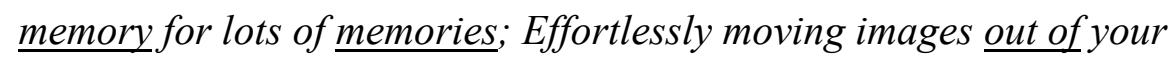
camera and into your life; fun, fun, fun!

- Alliteration: deep depth; Smooth, Stable, and Always Able; Shoot ' $n$ ' Share; Ideal for teens and tweens.

These findings are similar to those found by Fuertes-Olivera et al. (2001), who also highlight the importance of foregrounding strategies, such as alliteration and repetition of letters, among others.

Finally, there are 26 examples of various types of reductions contributing to the informal style in our corpus:

- Clipping: specs, apps, info, decor, mic, pics, (e.g. add new pics online)

- Lack of auxiliaries in questions: e.g. Want a still photo instead of video? And if you're feeling adventurous, why not give the email address to a friend? See more products by Kodak?

- Subject omission: Comes ready to use with 12 World Heritage Traveler(TM) photos included. Can't get enough of VIDEO GAMES?

Summing up, the interpersonal function of language is represented in our corpus by means of several different linguistic devices, with a notable frequency in the use of the second person pronoun and imperatives. Advertisers try to convince prospective 
consumers by imitating informal conversations (Fuertes-Olivera et al., 2001, p. 1295; Janoschka, 2004), including exclamation marks, language play, subject omission, alliteration, and so on.

\section{Conclusions}

This study is a corpus-based analysis of the rhetorical structure and the expression of persuasion in English online advertisements of electronic products. An English-Spanish comparable corpus was collected and tagged for rhetorical moves. A rhetorical structure for this subgenre was set up and compared in the two working languages. The main conclusion we can draw in this section is that, surprisingly, explicit persuasive steps do not occur in $100 \%$ of texts, unlike objective characteristics. It was also noticed that in English there seem to be clearer boundaries between the different rhetorical sections of the texts. From a cross-linguistic perspective, the rhetorical structure of online advertisements was found to be very similar in English and Spanish.

As for the lexico-grammatical analysis, only the English persuasive move was studied in detail for the purpose of this paper. The devices identified for the expression of positive evaluation in English include emphatic enumeratives, multiple modifiers, multal quantifying expressions, non-finite clauses, and so on. In addition, informal style is constantly employed in the texts in our corpus, represented by the use of imperatives, the second person pronoun, the clipping of common words, contractions, omissions of subjects and auxiliaries, and idiomatic expressions in general.

The findings of this study provide non-native speakers of English with rhetorical guidelines and an inventory of lexico-grammatical resources that may help them in successfully writing persuasive texts in English, in particular advertisements for electronic products. As Bhatia claims, "generic competence is an important contributor to professional expertise" (Bhatia, 2004, p. 145), and we claim in this paper that nonnative speakers may be trained to achieve this generic competence in a foreign language by carefully considering the means employed by native speakers to write texts belonging to a particular genre or subgenre.

All the linguistic data obtained from the analysis described in this paper have been used to construct a computer program to assist non-native speakers in writing online advertisements of electronic products in English. This text generator was registered by the University of León, Spain, under the Spanish acronym GDPE 
(Generador de Descripciones de Productos Electrónicos) with reference number LE-362013. The interface of the home page can be seen in Appendix C. A demo is available at the URL: http://contraste2.unileon.es/web/es/applications.html. Other generators are also available as demo versions at the same URL and more are currently under construction, all within the framework of the ACTRES research project. The present study, therefore, has contributed relevant information for building an electronic tool for professional writing.

\section{Acknowledgments}

This paper was partially funded by Project FFI2009-08548 awarded by the Spanish Ministry for Science and Technology and by Project LE025A09 awarded by the Regional Government (Junta de Castilla y León, Spain).

\section{References}

Barron, A. (2006). Understanding spam: A macro-textual analysis. Journal of Pragmatics, 38(6), 880-904.

Bhatia, V. K. (1993). Analysing Genre: Language Use in Professional Settings. London: Longman.

Bhatia, V. K. (2004). Worlds of Written Discourse. London: Continuum.

Biber, D., Connor, U. \& Upton, T. (2007).Discourse on the Move. Amsterdam: John Benjamins.

Brett, P.A. (1994). A genre analysis of the Results sections of Sociology articles. English for Specific Purposes, 13(1), 47-60.

Connor, U., \& Mauranen, A. (1999). Linguistic analysis of grant proposals: European Union research grants. English for Specific Purposes, 18, 47-62.

Cook, G. (2001). The Discourse of Advertising. London: Routledge.

Díez-Fernández, M. A. (2009). English-Spanish Contrastive Analysis of Football Match Reports in Printed Press. From Description to Applications. Unpublished PhD Thesis. University of León, Spain.

Dudley-Evans, A. (1994). Genre analysis: An approach for text analysis for ESP. In M. Coulthard (Ed.) Advances in Written Text Analysis, (pp. 219-228). London: Routledge.

Fairclough, N. (1989). Language and Power. London: Longman. 
Fairclough, N. (1992). Discourse and Social Change. Cambridge: Polity Press.

Firth, J.R. (1957).Papers in Linguistics.1934-1951. London: Oxford University Press.

Fuertes-Olivera, P. A., Velasco-Sacristán, M., Arribas-Baño, A. \& Samaniego-

Fernández, E.(2001). Persuasion and advertising English: Metadiscourse in slogans and headlines. Journal of Pragmatics, 33, 1291-1307.

Halliday, M. A. K. (2004). An Introduction to Functional Grammar ( ${ }^{\text {rd }}$ ed.). London: Arnold.

Hatim, B. (1990). The fuzzy nature of discourse in the translation process: Towards a text-based pedagogy of translation. In G.M. Anderman \& M.A. Rogers (Eds.), Translation in teaching and teaching translation (pp. 105-124). Guildford: University of Surrey.

Hiranburana, K. (1996). Cross-Cultural Strategies and the Use of English in International Business Correspondence. Unpublished PhD Thesis. Flinders University of South Australia, Australia.

Hyland, K.(1998). Persuasion and context: The pragmatics of academic metadiscourse. Journal of Pragmatics, 30, 437-455.

Janoschka, A. (2004). Web Advertising. New forms of Communication on the Internet. Amsterdam/ Philadelphia: John Benjamins.

Leech, G. N. (1966). English in Advertising: A linguistic study of advertising in Great Britain. London: Longman.

López-Arroyo, B., Fernández-Antolín, M. \& de-Felipe-Boto, R. (2007). Contrasting the rhetoric of abstracts in medical discourse. Implications and applications for English Spanish translation. Languages in Contrast, 7(1), 1-28.

Martín-Martín, P. (2003). A genre analysis of English and Spanish research paper abstracts in experimental and social sciences. English for Specific Purposes, 22, $25-43$.

Martín-Martín, P. (2005). The Rhetoric of the Abstract in English and Spanish Scientific Discourse. Bern: Peter Lang.

Mauranen, A. (1993). Contrastive ESP rhetoric: Metatext in Finnish-English economics texts. English for Specific Purposes, 12, 3-22.

Myers, G. (1994). Words in Ads. London: Arnold.

Myers, G. (1999). Ad Worlds: Brands, Media, Audiences. London: Arnold.

Precht, K. (2000). Patterns of stance in English. Unpublished dissertation, Northern Arizona University, Flagstaff. 
Rush, S. (1998). The noun phrase in advertising English. Journal of Pragmatics, 29, $155-171$.

Salager-Meyer, F. (1990). Discourse flaws in medical English abstracts: A genre analysis per research and text type. Text, 10(4), 365-384.

Simpson, P. 2001. 'Reason' and 'tickle' as pragmatic constructs in the discourse of advertising. Journal of Pragmatics, 33 (4), 589-607.

Suárez, L., \& Moreno, A. (2008). The rhetorical structure of academic book review of literature. An English-Spanish cross-linguistic approach. In U. Connor, E. Nagelhout \& W.V. Rozycki (Eds.), Contrastive Rhetoric. Reaching to Intercultural Rhetoric (pp. 147-167). Amsterdam/Philadelphia: John Benjamins.

Swales, J. (1990). Genre Analysis: English in Academic and Research Settings.

Cambridge: Cambridge University Press.

Swales, J. (2004). Research Genres. Explorations and Applications. Cambridge: Cambridge University Press.

Upton, T., \& Connor, U. (2001). Using computerized corpus analysis to investigate the textlinguistic discourse moves of a genre. English for Specific Purposes, 20, $313-329$

Valero-Garcés, C. (1996). Contrastive ESP rhetoric: Metatext in Spanish-English economics texts. English for Specific Purposes, 15(4), 279-294.

Vergaro, C. (2004). Discourse strategies of Italian and English sales promotion letters. English for Specific Purposes, 23(2), 181-207.

Williams, I.A. (2012). Cultural differences in academic discourse. In S. Marzo, K. Heylen \& G. De Sutter (Eds.), Corpus Studies in Contrastive Linguistics (pp. 63-88). Amsterdam/Philadelphia: John Benjamins.

Yus, F. (2011). Cyberpragmatics. Internet-mediated Communication in Context. Amsterdam/Philadelphia: John Benjamins.

Zhou, S. (2012). 'Advertorials': A genre-based analysis of an emerging hybridized genre. Discourse and Communication, 6(3), 323-346.

Zhu, Y. (2001). Comparing English and Chinese Persuasive Strategies in Trade Fair Invitations. Document Design, 2(1), 2-17. 
APPENDIX A: Sample original online advertisement in English.

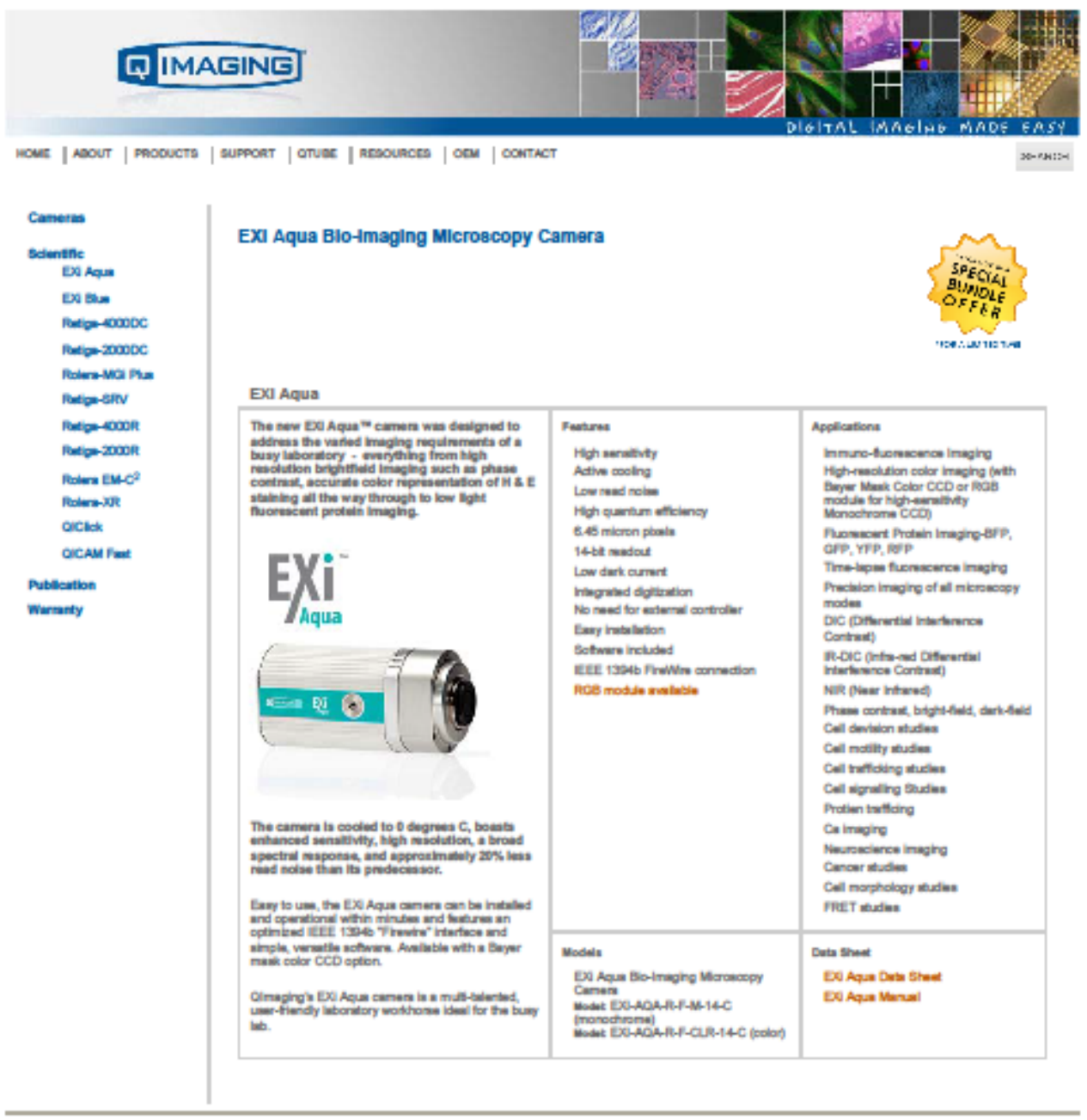

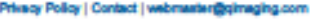


APPENDIX B: Coded online advertisement in English.

$<$ MOVE 1: IDENTIFYING PRODUCT AND PURPOSE $>$

$<$ NAMING THE PRODUCT $>$ EXi Aqua Bio-Imaging Microscopy Camera

EXi Aqua $<$ /NAMING THE PRODUCT $>$

$<$ STATING THE APPLICATIONS $>$ The new EXi Aqua ${ }^{\text {TM }}$ camera was designed to address the varied imaging requirements of a busy laboratory - everything from high resolution brightfield imaging such as phasecontrast, Accurate color representation of $\mathrm{H} \& \mathrm{E}$ staining all the way through to low light fluorescent protein imaging. $</$ STATING THE APPLICATIONS $>$

$<$ ILLUSTRATING THE PRODUCT WITH A PICTURE $>$ picture $</$ ILLUSTRATING THE PRODUCT WITH A PICTURE>

$<$ MOVE 1: IDENTIFYING PRODUCT AND PURPOSE $>$

$<$ MOVE 2: DESCRIBING THE PRODUCT $>$

$<$ PERSUASIVE CHARACTERISTICS $>$

$<$ EVALUATING THE PRODUCT POSITIVELY $>$ The camera is cooled to 0 degrees $\mathrm{C}$, boasts enhanced sensitivity, high resolution, a broad spectral response $<$ /EVALUATING THE PRODUCT POSITIVELY $>$, $<$ COMPARING THE PRODUCT WITH OTHER SIMILAR PRODUCTS $>$ and approximately $20 \%$ less read noise than its predecessor. $</$ COMPARING THE PRODUCT WITH OTHER SIMILAR

PRODUCTS>

$<$ EVALUATING THE PRODUCT POSITIVELY $>$ Easy to use, the EXi Aqua camera can be installed and operational within minutes and features an optimized IEEE 1394b "Firewire" interface and simple, versatile software. $<$ /EVALUATING THE PRODUCT POSITIVELY>

$<$ PERSUASIVE CHARACTERISTICS $>$

$<$ OBJECTIVE CHARACTERISTICS $>$

$<$ LISTING EXTRA OPTIONS $>$

Available with a Bayer mask color CCD option.

$<$ LISTING EXTRA OPTIONS $>$

$<$ OBJECTIVE CHARACTERISTICS $>$

$<$ PERSUASIVE CHARACTERISTICS $>$

QImaging'sEXi Aqua camera is a multi-talented, user-friendly laboratory workhorse ideal for the busy lab.

$<$ /PERSUASIVE CHARACTERISTICS $>$

\section{$<$ OBJECTIVE CHARACTERISTICS $>$}

$<$ LISTING FEATURES $>$

Features

High sensitivity

Active cooling

Low read noise

High quantum efficiency

6.45 micron pixels

14-bit readout

Low dark current

Integrated digitization

No need for external controller

Easy installation

Software included

IEEE 1394b FireWire connection

RGB module available

$</$ LISTING FEATURES $>$

$<$ LISTING MODELS $>$

Models

EXi Aqua Bio-Imaging MicroscopyCamera

Model: EXI-AQA-R-F-M-14-C (monochrome)

Model: EXI-AQA-R-F-CLR-14-C (color)

$</$ LISTING MODELS $>$ 
$</$ MOVE 2: DESCRIBING THE PRODUCT $>$

$<$ MOVE 1: IDENTIFYING PRODUCT AND PURPOSE $>$

$<$ STATING THE APPLICATIONS $>$

Applications

Immuno-fluorescence Imaging

High-resolution color imaging (withBayer Mask Color CCD or RGBmodule for highsensitivitymonochrome CCD)

Fluorescent Protein Imaging-BFP,GFP, YFP, RFP

Time-lapse fluorescence imaging

Precision imaging of all microscopymodes

DIC (Differential InterferenceContrast)

IR-DIC (Infra-red DifferentialInterference Contrast)

NIR (Near Infrared)

Phase contrast, bright-field, dark-field

Cell devision studies

Cell motility studies

Cell trafficking studies

Cell signalling Studies

Protientrafficing

Ca imaging

Neuroscience imaging

Cancer studies

Cell morphology studies

FRET studies

$<$ STATING THE APPLICATIONS $>$

$<$ MOVE 1: IDENTIFYING PRODUCT AND PURPOSE $>$

$<$ MOVE 2: DESCRIBING THE PRODUCT $>$

$<$ OBJECTIVE CHARACTERISTICS $>$

$<$ LISTING DATA SHEET $>$

Data Sheet

EXi Aqua Data Sheet

EXi Aqua Manual

$<$ LISTING DATA SHEET $>$

$<$ OBJECTIVE CHARACTERISTICS $>$

$<$ MOVE 2: DESCRIBING THE PRODUCT $>$ 
APPENDIX C: Interface of the Generator of Advertisements of Electronic Products.

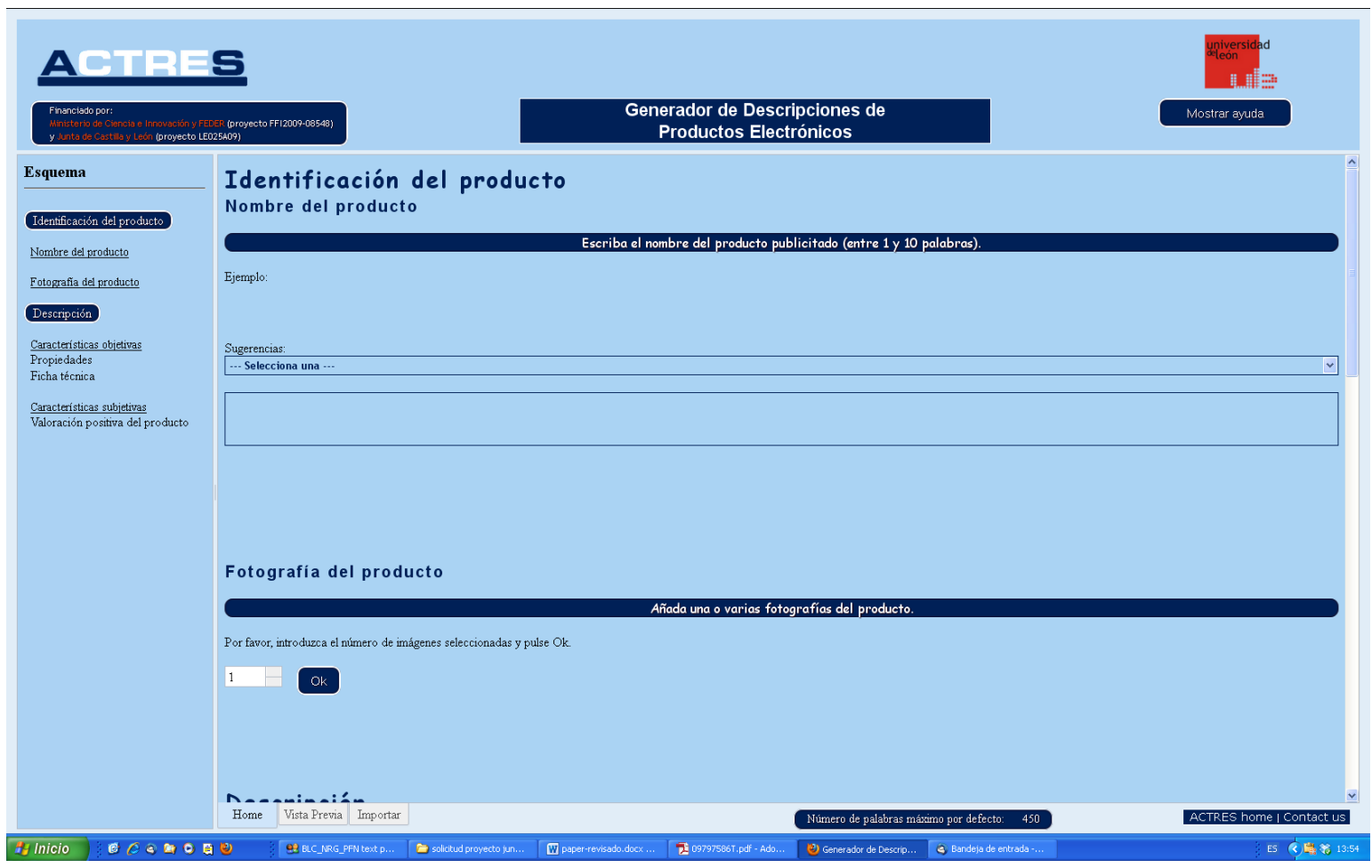

